\section{SDS-Polyacrylamide Gel Electrophoretic Analysis of Proteins in the Pres- ence of Guanidinium Hydrochloride}

\section{BioTechniques 20:376-378 (March 1996)}

The chaotropic properties of guanidinium hydrochloride $(\mathrm{GuHCl})$ cause unfolding and solubilization of proteins not normally soluble in physiologic solutions. This property has led to the wide use of $\mathrm{GuHCl}$ for the extraction of extracellular matrix compounds, such as proteoglycans from tissues, and, more recently, for solubilizing recombinant proteins from bacterial inclusion bodies. A major drawback to the use of $\mathrm{GuHCl}$ is its incompatibility with polyacrylamide gel electrophoresis (PAGE) in the presence of sodium dodecyl sulfate (SDS). The chloride ions in $\mathrm{GuHCl}$ cause a disruption in the voltage gradient of the electrophoretic column and the guanidinium causes precipitation of the SDS. Conventional methodology calls for a $10 \%-25 \%$ dilution of the sample containing $\mathrm{GuHCl}$ or a removal of the $\mathrm{GuHCl}$ by dialysis against a compatible chaotropic agent such as 8 $M$ urea before addition of SDS-containing sample buffer. These procedures are effective but can be time-consuming if they need to be carried out on multiple samples, such as in the analysis of fractions from a chromatography column.

We have devised a simple method that removes $\mathrm{GuHCl}$ from protein samples and can serve to concentrate dilute proteins simultaneously. The method involves adsorption of the proteins on a nitrocellulose membrane, staining of the protein with the dye Ponceau S, cutting out the stained membrane and eluting the proteins from the membrane in the presence of SDS-containing sample buffer. Figure 1 shows separation of a recombinant form of the protein bovine lumican (2) solubilized from bacterial inclusion bodies after lysis of the $E s$ cherichia coli host and removal of soluble material by centrifugation (4). Insoluble recombinant proteins, dissolved in $4 \mathrm{M} \mathrm{GuHCl}$, were separated on a size exclusion column of Superdex ${ }^{\circledR}-200$
(Pharmacia Biotech, Piscataway, NJ, USA) in the presence of $4 \mathrm{M} \mathrm{GuHCl}$. Protein from column fractions was adsorbed onto a nitrocellulose membrane by passing $10 \mu \mathrm{L}$ of each fraction, diluted to $100 \mu \mathrm{L}$ with $4 \mathrm{M} \mathrm{GuHCl}$, through a vacuum dot-blot apparatus (Bio-Rad, Hercules, CA, USA). The membrane was briefly rinsed in $1 \%$ acetic acid, stained in $0.1 \%$ Ponceau $\mathrm{S}$ dye (Sigma Chemical, St. Louis, MO, USA) in $1 \%$ acetic acid for $1 \mathrm{~min}$ and destained with 2-4 changes of $1 \%$ acetic acid over a period of $2-5 \mathrm{~min}$. A photograph of the stained protein dots is shown above the graph in Figure 1. The damp membrane was laid on two layers of filter paper, and each stained dot was cut out with a sharpened 4mm-diameter cork borer, then transferred to a $1.5-\mathrm{mL}$ polypropylene centrifuge tube. The excised circles were covered with $20 \mu \mathrm{L}$ of SDS sample buffer (1\% SDS, $10 \%$ glycerol, $1 \% \beta$ mercaptoethanol, $0.1 \mathrm{M}$ Tris- $\mathrm{HCl}, \mathrm{pH}$ 6.8) and heated to $70^{\circ} \mathrm{C}$ for $20 \mathrm{~min}$. The samples were vortex mixed and centrifuged briefly, and a portion of each was loaded in a sample well of a $12 \%$ SDS-PAGE minigel. Electrophoresis was carried out as previously described (3), and the gel was stained for $1-2 \mathrm{~h}$ in $0.05 \%$ (wt/vol) Coomassie ${ }^{\circledR}$ Blue dye in $10 \%$ acetic acid after a preliminary fixation in $25 \%$ isopropanol, $10 \%$ acetic acid for $20 \mathrm{~min}$. Destaining is not

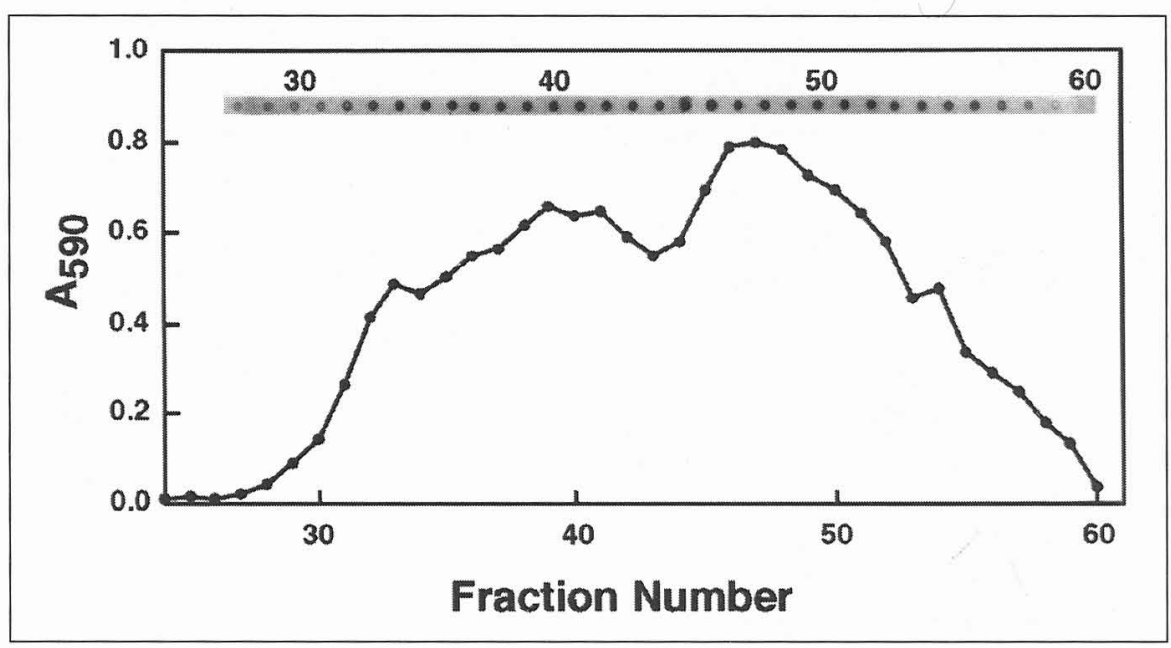

Figure 1. Dot-blot detection of protein in chromatography fractions containing GuHCl. Insoluble protein from a bacterial lysate expressing recombinant bovine lumican protein was dissolved in $4 \mathrm{M}$ $\mathrm{GuHCl}, 0.02 \mathrm{M}$ Tris- $\mathrm{HCl}, \mathrm{pH} 8.0$, and clarified by centrifugation. About $4 \mathrm{mg}$ of this protein was injected on a $1-\times 30-\mathrm{cm}$ size exclusion column of Superdex 200 and eluted in $4 \mathrm{M} \mathrm{GuHCl}, 0.02 \mathrm{M}$ Tris- $\mathrm{HCl}$, $\mathrm{pH} 8.0$, at $0.25 \mathrm{~mL} / \mathrm{min}$. One-minute fractions were collected and $10 \mu \mathrm{L}$ of each fraction were adsorbed to nitrocellulose membrane and stained with Ponceau S dye as described in the text. The graph shows total protein as detected by the Bradford assay (1). A photograph of the stained nitrocellulose membrane shows alignment of fraction numbers with the stained protein dots.

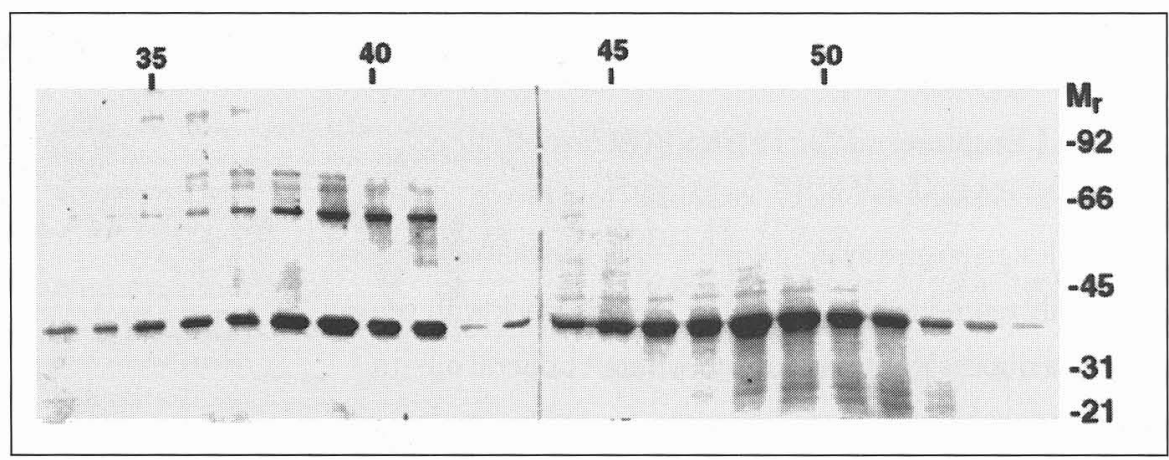

Figure 2. SDS-PAGE analysis of dot-blotted proteins. Stained protein dots shown in Figure 1 were excised from the damp membrane with a cork borer, proteins eluted in SDS-PAGE sample buffer and the proteins subjected to electrophoresis as described in the text. The Coomassie-stained proteins from two gels are shown with the corresponding fraction numbers. 
necessary under these conditions. SDSPAGE of proteins separated from the stained dots in Figure 1 is shown in Figure 2.

The sensitivity of the method was examined in Figure 3. In terms of total protein, the lower limit of detection was $1-2 \mu \mathrm{g}$ of each protein, making the technique $20 \%-50 \%$ as sensitive as electrophoresis, and the staining was carried out without the preliminary blotting. The reduced sensitivity resulting from the blotting step, however, is offset by the fact that adsorption onto nitrocellulose serves to concentrate proteins. Figure 3 illustrates that solutions of protein of $2 \mu \mathrm{g} / \mathrm{mL}$ (about 10 fold more dilute than can normally be analyzed) are readily detected after concentration by dot-blotting. Densitometry of the stained bands (Figure 3B) showed that linearity was lost above 30 $\mu \mathrm{g}$ of total protein (equivalent to protein of about $100 \mu \mathrm{g} / \mathrm{sq} \mathrm{cm}$ ), suggesting that the membrane was becoming saturated at these levels.

This procedure provides an efficient way of preparing multiple SDS-PAGE samples. Those shown in Figures 1 and 2 required less than one hour from setting up the dot-blot apparatus to start-

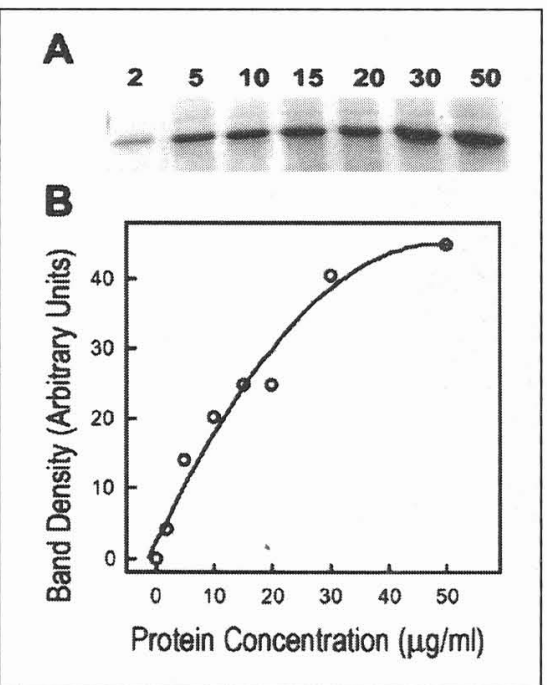

Figure 3. Sensitivity and range of the technique. One milliliter of recombinant lumican protein in $4 \mathrm{M} \mathrm{GuHCl}$ at concentrations of $2-50$ $\mu \mathrm{g} / \mathrm{mL}$ was dot-blotted onto nitrocellulose and subjected to electrophoresis as described in the text. Stained bands are shown in (A) with the concentration of the protein above each. Intensity of staining was determined by densitometry of the stained gel, and a plot of integrated band intensity vs. protein concentration is shown in (B). ing the electrophoresis, allowing the entire procedure from injection of the sample on the chromatography column to photography of the stained SDSPAGE gel to be carried out in a single 8-h working day. The use of a vacuum dot-blot apparatus allows application of proteins contained in samples of $1 \mathrm{~mL}$ or more onto a single gel lane by concentrating dilute protein samples and removing $\mathrm{GuHCl}$ in a single simple procedure. In the presence of high protein concentrations $(1 \mathrm{mg} / \mathrm{mL}$ or more), we found that direct spotting of $2 \mu \mathrm{L}$ of the proteins on the membrane obviated the need for the dot-blot apparatus. The dot-blot apparatus also can be avoided by multiple spotting of $2-\mu \mathrm{L}$ portions of more dilute samples, alternating with rinsing and drying the membrane; however, this procedure compromises the efficiency of the method.

Some caveats need to be observed using this method. First, detergents such as CHAPS or Triton ${ }^{\circledR}$ X-100 can interfere with binding of proteins to the membrane, and careful controls should be run if they are present in the protein solution. Second, when protein solutions are concentrated so that the amount of protein applied to the membrane exceeds the binding capacity of the membrane, hydrophobic proteins may bind to the membrane more efficiently than smaller hydrophilic proteins and produce a gel pattern not representative of the composition of the original sample. Within these limits, however, the method provides a rapid means of solving a potentially common and often troublesome technical problem that can affect productivity in the biotechnology laboratory.

\section{REFERENCES}

1.Bradford, M.M. 1976. A rapid and sensitive method for the quantitation of microgram quantities of protein utilizing the principle of protein-dye binding. Anal. Biochem. 72:248254.

2.Funderburgh, J.L., M.L. Funderburgh, S.J. Brown, J.P. Vergnes, J.R. Hassell et al. 1993. Sequence and structural implications of a bovine corneal keratan sulfate proteoglycan core protein. J. Biol. Chem. 268:1187411880.

3.Jost, C.J., J.L. Funderburgh, M. Mann, J.R. Hassell, G.W. Conrad. 1991. Cell-free translation and characterization of corneal keratan sulfate proteoglycan core proteins. J. Biol. Chem. 266:13336-13341.
4.Sambrook, J., E.F. Fritsch and T. Maniatis. 1989. Molecular Cloning: A Laboratory Manual. Cold Spring Harbor Laboratory Press, Cold Spring Harbor, NY.

This work was supported by NIH Grant EY09368 and American Heart Association, Kansas Affiliate Grant-In-Aid KS-94-GS-11 (to J.L.F.), and NIH Grant EY00952 (to Gary W. Conrad). Address correspondence to James Funderburgh, Division of Biology, Ackert Hall, Kansas State University, Manhattan, KS 66506-4901, USA. Internet: jlfunder@ksu.ksu.edu

Received 26 June 1995; accepted 28 September 1995.

\section{James L. Funderburgh and Sujatha Prakash Kansas State University Manhattan, KS, USA}

